\title{
Analysis of Energy Efficiency of Domestic Refrigerators
}

\section{G.S.R. Costa and D.D. Ananda Namal}

\begin{abstract}
As refrigerator is a very common appliance in almost every household and it is the number one domestic appliance which operates whole day, it tends to consume a considerable amount of energy out of the whole country's domestic energy consumption. Personal as well as national level benefits can be achieved if energy efficient refrigerators were identified from available refrigerator types in the market. When empirical and theoretical results are perused it comes to note that there is no study done to understand the energy efficiency of various types of refrigerators by analyzing a large sample of real data. This study is a quantitative analysis of energy consumption of more than 40 samples of experimental results of key types of domestic refrigerators. The experiments were conducted inside a testing laboratory and energy consumption pattern was obtained from tested data. By analyzing the results, it was observed that inverter refrigerators are $22 \%$ energy efficient than normal automatic defrosting refrigerators and 10\% energy efficient than manual defrosting refrigerators. This outcome is mainly beneficial to general public as well as energy conservation policy makers for future decision making. It is recommended to promote inverter refrigerators for the case of national benefit.
\end{abstract}

Keywords: Energy efficiency, Energy consumption, Domestic refrigerator

\section{Introduction}

Refrigerator is an essential and most popular appliance in many houses and it is predominantly used for preserving food. In order to achieve better quality of food until consumption, constant running of refrigerator is desirable. This phenomenon leads to a substantial amount of energy consumption. To reduce energy consumption systematic controlling is essential, because adhoc controlling could severely affect the quality of food and may cause serious food poisoning which might be fatal. Considering this aspect, energy saving with proper performance of the refrigerator is essential.

\subsection{Refrigerator Energy Use}

Domestic refrigerator is featured for household requirements and consists of a small freezer with ice making capability, normally located at the top, and a fresh food compartment for fresh fruits and vegetables. Refrigerators are free standing or built in types with vapor compression refrigeration systems. Refrigerator consumes energy to maintain the temperature inside its compartments.

One of the major factors that disrupt the maintenance of temperature inside the refrigerator compartments is the frost formation inside the freezer. Frost formation is controlled by two methods, manual defrosting and automatic defrosting.

\subsection{Manual Defrosting Refrigerators}

Early generation of refrigerators used cold wall technology to maintain compartment temperature. In this technology, a refrigerant circulates through tubing in the walls. Temperature difference inside the compartment will promote the cool air to circulate throughout the unit. In this case, fog is built up on interior walls of the refrigerator and when it becomes denser it acts as a barrier to the heat transfer through the wall. In order to prevent this happening, periodic frost removal process should be carried out.

\subsection{Automatic Defrosters}

In an automatic defrosting refrigerator, an evaporator coil is inside the enclosed housing ceiling and walls. By using forced air technology, cool air is circulated throughout the compartment by a fan.

Eng. G.S.R. Costa, B.Sc. Eng. (Moratuwa), AMIE(SL).

Research Engineer, National Engineering Research and

Development Centre.

Email:roshanisep@yahoo.co.in

ORCID ID: $h$ ttp://orcid.org/0000-0002-8611-4396

Eng. D.D. Ananda Namal, M.Eng.(Moratuwa), C.Eng., MIE(SL) B.Sc. Eng. (Peradeniya), Director General,

National Engineering Research and Development Centre.

Email:namaltilla@gmail.com

ORCID ID: http://orcid.org/0000-0003-2341-9480 
In this method, formation of frost will be eliminated inside the freezer because cold air, which has a lower humidity level, absorbs any ice formed. If freezer door is opened fan will stop to prevent warm air circulation inside the cabinet.

Frost may build up on evaporator coil inside the housing. There is a heating element inside the housing with evaporator coil periodically heating up the frost on the evaporator coil and draining out from the freezer and evaporating. These refrigerators consume energy basically for periodic heating to remove frost.

Refrigerator energy requirement to maintain temperature inside the compartments is highly dependent on the compressor efficiency, the device consuming more than $90 \%$ of its energy. The compressor of domestic refrigerators available today is of two types, viz. fixed speed compressors and variable speed compressors on inverter circuit.

\subsection{Automatic Defrosters with Digital Inverter Compressor}

Usual compressor control method is ON/OFF method where compressor is selected to run at its maximum capacity which is its peak load capacity. But the real situation is different because, most of the time, the refrigerator is at a closed door situation and refrigerator is not always fully loaded. Further, surrounding temperature and relative humidity varies, so variable speed compressor for varying load should consume less energy than fixed speed compressor.

\subsection{Energy Efficiency and Efficiency \\ Rating}

Energy efficiency of a refrigerator is the effective energy output of the refrigerator to the total energy input to the refrigerator, inverse of this is efficiency rating.

\subsection{Mathematical Model for Efficiency \\ Rating}

Effective cooling output to energy consumption was obtained from the theoretical formulation given in Eq (1), which was derived by applying energy balance equation to the compartments of the refrigerator,

Total Energy in refrigerator $\left(E_{1}\right)=$ Energy in Freezer volume + Energy in Fresh Food Compartment volume

$E_{1}=m_{f}\left(h_{f}+z_{f}+K . E_{f}\right)+m_{c}\left(h_{c}+z_{c}+K \cdot E_{c}\right)$

Where, $m_{f}=$ mass of air volume in the freezer compartment $(\mathrm{kg})$ $m_{c}=$ mass of air volume of fresh food

compartment $(\mathrm{kg})$

$h_{f}=$ specific enthalpy of freezer volume

$(\mathrm{kJ} / \mathrm{kgK})$

$h_{c}=$ specific enthalpy of fresh food

compartment volume $(\mathrm{kJ} / \mathrm{kgK})$

$z_{f}=$ Potential energy of freezer volume

$(\mathrm{kJ} / \mathrm{kgK})$

$z_{c}=$ Potential energy of fresh food compartment

volume $(\mathrm{kJ} / \mathrm{kgK})$

$K . E_{f .}=$ Kinetic energy of freezer volume

$K . E_{c}=$ Kinetic energy of fresh food

compartment

Eq.(1) can be simplified as follows.

There is no kinetic work and no potential change during the test period,

$z_{f}, z_{c}=0 ; K . E_{f \cdot}, K \cdot E_{c}=0$

$E_{1}=m_{f}\left(h_{f}\right)+m_{c}\left(h_{c}\right)$

$m_{f}=d_{f} x V_{f}$

and $m_{c}=d_{c} x V_{c}$

$V_{f}=$ Freezer volume (measured in $l$ )

Where, $V_{c}=$ Fresh food compartment volume (measured in 1 )

$d_{f}, d_{c}$ is Air density, $\simeq 1 \mathrm{~kg} / \mathrm{m}^{3} \simeq 1 \mathrm{~g} / 1$

$E_{1}=d_{f} V_{f} h_{f}+d_{c} V_{c} h_{c} \quad(\mathrm{~J})$

$E_{1}=V_{f} h_{f}+V_{c} h_{c}$

$E_{1}=C_{p} V_{f}\left(T_{r}-T_{f}\right)+C_{p} V_{c}\left(T_{c}-T_{f}\right)$

Where $C p=$ Specific heat of air at constant pressure $\simeq 1(\mathrm{~kJ} / \mathrm{kgK})$ at ambient temperature.

Then;

$E_{1}=V_{f}\left(T_{r}-T_{f}\right)+V_{c}\left(T_{c}-T_{f}\right)$

In other words, $E_{1}$ can be extracted as useful energy.

Where

$T_{f}=$ Average freezer temperature $\left({ }^{\circ} \mathrm{C}\right)$

$T_{c}=$ Average fresh food compartment temperature $\left({ }^{\circ} \mathrm{C}\right)$

$T_{r}=$ Room temperature during the test $\left({ }^{\circ} \mathrm{C}\right)$

$E_{c}=$ Energy input or consumption in $\mathrm{kWh}$

$E_{c}$ can be measured by power meter.

Efficiency Rating $\left(E_{r}\right)=\frac{\text { Energy input }(\mathrm{kWh})}{\text { Useful Energy output }(\mathrm{kWh})}$

$$
\begin{array}{r}
E_{r}=\left(\frac{E_{c}}{E_{1}}\right) \\
E_{r}=\frac{E_{c}}{V_{f}\left(T_{r}-T_{f}\right)+V_{c}\left(T_{c}-T_{r}\right)}
\end{array}
$$

Lower the $E_{r}$, then higher the performance of the refrigerator. 


\section{Material and Method}

\section{1 Test Units}

Forty-one numbers of domestic refrigerators from different brands and models of inverter and non-inverter type were selected. Noninverter refrigerators consisted of manual defrosting and automatic defrosting technologies.

\section{$2.2 \quad$ Testing Facility}

Refrigerators were tested in the refrigerator testing laboratory at National Engineering Research and Development Centre (NERDC). ConstChamber is the software used to control the laboratory ambient temperature and humidity and for data logging.

\subsection{Testing Methodology}

Refrigerators were tested under controlled laboratory conditions. Room temperature (inside testing chamber) was maintained at $32^{\circ} \mathrm{C}$ and relative humidity was controlled between $70 \%-80 \%$, which compares well with the general environmental conditions of subtropical climate zones. These conditions were maintained throughout the test period.

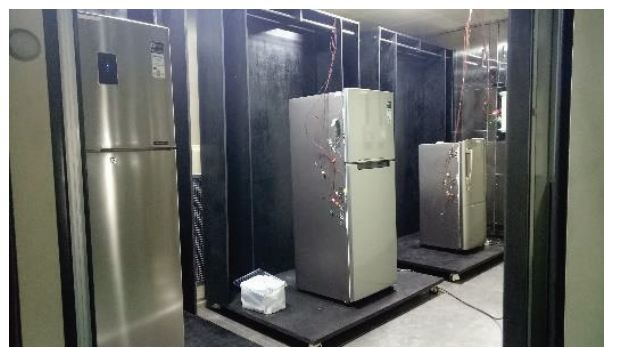

Figure 1 - Refrigerator Testing Laboratory at NERDC

$\mathrm{T}$-type thermocouples were used to sense the temperature at several locations inside the refrigerator. Temperature sensors and power meter readings were logged at 5 second intervals throughout the test period. Power meters attached to the test chamber were used to measure energy consumption of refrigerator compartments. Experiment set up was in accordance with the Sri Lankan Standard of SLS 1230:2003 [1].

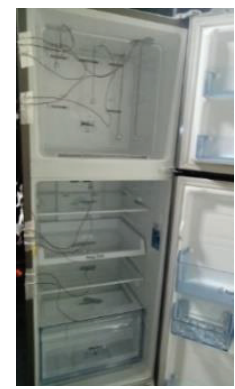

Figure 2 - Typical Picture of Temperature Sensors attached to Refrigerator Compartments
Temperature sensors were located fairly evenly across the volume considered, and as per the SLS 1230:2003 standard.

Prior to the test, refrigerators were allowed to operate not less than $24 \mathrm{~h}$ to ensure working condition of mechanical parts and to achieve the stabilized performance. Regulators of refrigerators which perform automatic defrosting of freezer were set by trial and error method to obtain $-15^{\circ} \mathrm{C}$ of average of freezer compartment and average of $5^{\circ} \mathrm{C}$ or near below temperatures at fresh food compartment. Direct coolers (refrigerators whose defrosting is manually operated) were set at $-9^{\circ} \mathrm{C}$ of average freezer temperature and avg. $5^{\circ} \mathrm{C}$ for fresh food compartment temperature. These temperatures are as per the recommendation of SLS 1230:2003 for automatic and manual defrosting refrigerators.

Using ConstChamber testing and monitoring software, refrigerators were tested and temperatures and power consumption data were recorded at five second intervals for a minimum of 16 hours or for a period of time where two defrost cycles were completed for automatic defrosters.

Energy input from power meter readings and average temperatures inside the freezer and fresh food compartment were obtained from the test results using ConstChamber software. Freezer and fresh food compartment internal volumes were measured.

\section{Analysis of Energy Efficiency}

Twelve numbers of inverter type automatic defrosting refrigerators were tested and results are tabulated in Table 1. Energy Rating $E_{r}$ was calculated using Eq.(3). Other parameters are directly taken from test results. In a similar manner, 13 numbers of automatic defrosting (AD) non-inverter refrigerators and 16 numbers of manual defrosting refrigerators were tested and results are tabulated in Table 2 and Table 3, respectively.

$E_{r}$ was plotted against each refrigerator (Figure 3 ), and results show that the distribution of $E_{r}$ of inverter refrigerators are below 0.15, but automatic non-inverter refrigerators had the comparatively high $\mathrm{E}_{\mathrm{r}}$ with maximum of 0.23 , while manual defrosting refrigerators had maximum $E_{r}$ of 0.19 . This implies that the energy consumption of inverter refrigerators is lower than non-inverters (non-inverter automatic and manual defrosting refrigerators). This is because when lower the $\mathrm{E}_{\mathrm{r}}$ then lower the energy consumption is (refer Eq. (3)). Average of $E_{r}$ for each refrigerator type was calculated and shown in Figure 4. 
Table 1 - Automatic Defrosting Inverter Refrigerators

\begin{tabular}{|c|c|c|c|c|c|c|}
\hline Refrigerator & $\mathbf{V}_{\mathbf{f}}(\mathbf{L})$ & $\begin{array}{c}\mathbf{E}_{\mathbf{C}} \text { for } \mathbf{2 4} \text { hours } \\
\mathbf{( k W h})\end{array}$ & $\begin{array}{c}\mathbf{E}_{\mathbf{1}} \\
\mathbf{( k J )}\end{array}$ & $\mathbf{T}_{\mathbf{c}}\left({ }^{\mathbf{0}} \mathbf{C}\right)$ & $\mathbf{T}_{\mathbf{f}}\left({ }^{\mathbf{}} \mathbf{C}\right)$ & $\mathbf{E}_{\mathbf{r}}$ \\
\hline 1 & 237 & 0.940 & 7.82 & 2.50 & -12.40 & 0.120 \\
\hline 2 & 244 & 0.986 & 7.42 & 5.00 & -16.00 & 0.123 \\
\hline 3 & 225 & 0.877 & 8.03 & 5.00 & -15.00 & 0.118 \\
\hline 4 & 167 & 0.874 & 5.94 & 3.00 & -17.00 & 0.147 \\
\hline 5 & 181 & 0.85 & 6.10 & 4.00 & -16.00 & 0.140 \\
\hline 6 & 239 & 1.012 & 7.66 & 3.00 & -15.00 & 0.127 \\
\hline 7 & 239 & 1.189 & 8.71 & 3.00 & -15.00 & 0.150 \\
\hline 8 & 239 & 1.065 & 8.38 & 3.00 & -15.00 & 0.134 \\
\hline 9 & 187 & 0.806 & 6.16 & 0.00 & -10.00 & 0.131 \\
\hline 10 & 248 & 1.168 & 8.41 & 2.00 & -15.00 & 0.138 \\
\hline 11 & 335 & 1.143 & 11.34 & 3.00 & -19.00 & 0.101 \\
\hline 12 & 198 & 0.631 & 6.70 & 3.00 & -17.00 & 0.093 \\
\hline Average & $\mathbf{2 2 8}$ & $\mathbf{0 . 9 6 2}$ & $\mathbf{7 . 7 2}$ & 3.04 & $\mathbf{- 1 5 . 2 0}$ & $\mathbf{0 . 1 2 7}$ \\
\hline
\end{tabular}

Table 2 - Automatic Defrosting Non- Inverter Refrigerators

\begin{tabular}{|c|c|c|c|c|c|c|}
\hline Refrigerator & $\mathbf{V}_{\mathbf{f}}(\mathbf{L})$ & $\begin{array}{l}\mathbf{E}_{\mathbf{C}} \text { for } \mathbf{2 4} \\
\text { hours }(\mathbf{k W h})\end{array}$ & $\begin{array}{c}\mathrm{E}_{\mathbf{1}} \\
\mathbf{( k J )}\end{array}$ & $\mathbf{T}_{\mathbf{c}}$ & $\mathbf{T}_{\mathbf{f}}$ & $\mathbf{E}_{\mathbf{r}}$ \\
\hline 1 & 194 & 1.299 & 6.47 & 4.50 & -16.52 & 0.201 \\
\hline 2 & 237 & 1.132 & 7.67 & 4.40 & -15.80 & 0.148 \\
\hline 3 & 237 & 1.243 & 8.71 & -1.20 & -16.30 & 0.143 \\
\hline 4 & 237 & 1.102 & 8.38 & 0.20 & -15.00 & 0.132 \\
\hline 5 & 237 & 1.099 & 8.09 & 2.70 & -17.80 & 0.136 \\
\hline 6 & 237 & 0.805 & 6.98 & 6.00 & -8.70 & 0.115 \\
\hline 7 & 190 & 1.506 & 6.98 & 3.90 & -19.10 & 0.230 \\
\hline 8 & 190 & 1.437 & 6.54 & 3.50 & -18.60 & 0.219 \\
\hline 9 & 190 & 1.339 & 6.54 & 3.90 & -20.30 & 0.203 \\
\hline 10 & 225 & 1.348 & 7.46 & 3.00 & -16.00 & 0.179 \\
\hline 11 & 226 & 1.035 & 7.61 & 3.00 & -15.00 & 0.138 \\
\hline 12 & 181 & 1.087 & 5.61 & 5.00 & -12.00 & 0.194 \\
\hline 13 & 198 & 0.808 & 6.73 & 4.00 & -18.00 & 0.120 \\
\hline Average & $\mathbf{2 1 4}$ & $\mathbf{1 . 1 7 2}$ & 7.21 & 3.30 & $-\mathbf{1 6 . 0 9}$ & $\mathbf{0 . 1 6 6}$ \\
\hline
\end{tabular}


Table 3 - Manual Defrosting Refrigerators

\begin{tabular}{|c|c|c|c|c|c|c|}
\hline Refrigerator & $\mathbf{V}_{\mathbf{f}} \mathbf{( L )}$ & $\begin{array}{l}\mathbf{E}_{\mathbf{C}} \text { for } \mathbf{2 4} \\
\text { hours } \\
\mathbf{( k W h}\end{array}$ & $\begin{array}{c}\mathbf{E}_{\mathbf{1}} \\
\mathbf{( k J )}\end{array}$ & $\mathbf{T}_{\mathbf{c}}$ & $\mathbf{T}_{\mathbf{f}}$ & $\mathbf{E}_{\mathbf{r}}$ \\
\hline 1 & 154 & 0.668 & 5.22 & 0.30 & -9.90 & 0.128 \\
\hline 2 & 187 & 0.771 & 6.26 & 1.70 & -11.50 & 0.123 \\
\hline 3 & 153 & 0.630 & 4.57 & -2.50 & -9.60 & 0.117 \\
\hline 4 & 180 & 0.637 & 5.10 & 0.10 & -9.30 & 0.107 \\
\hline 5 & 129 & 0.728 & 5.76 & 0.60 & -9.20 & 0.174 \\
\hline 6 & 208 & 0.996 & 6.70 & 3.00 & -11.00 & 0.149 \\
\hline 7 & 159 & 0.672 & 5.10 & 2.00 & -9.00 & 0.131 \\
\hline 8 & 154 & 0.660 & 4.80 & 4.00 & -10.00 & 0.138 \\
\hline 9 & 178 & 1.020 & 5.60 & 4.00 & -10.00 & 0.182 \\
\hline 10 & 144 & 0.864 & 4.57 & 3.00 & -9.00 & 0.189 \\
\hline 11 & 106 & 0.535 & 3.38 & 2.00 & -9.00 & 0.159 \\
\hline 12 & 145 & 0.864 & 4.33 & 5.00 & -9.00 & 0.199 \\
\hline 13 & 197 & 0.671 & 7.13 & -1.00 & -16.00 & 0.093 \\
\hline 14 & 171 & 0.800 & 6.36 & -2.00 & -15.00 & 0.131 \\
\hline 15 & 169 & 0.515 & 5.86 & 0.00 & -9.00 & 0.091 \\
\hline 16 & 167 & 0.471 & 5.76 & 0.00 & -10.00 & 0.084 \\
\hline Average & $\mathbf{1 6 2}$ & $\mathbf{0 . 7 1 9}$ & $\mathbf{5 . 4 1}$ & $\mathbf{1 . 2 6}$ & $\mathbf{- 1 0 . 4 1}$ & $\mathbf{0 . 1 4 0}$ \\
\hline
\end{tabular}

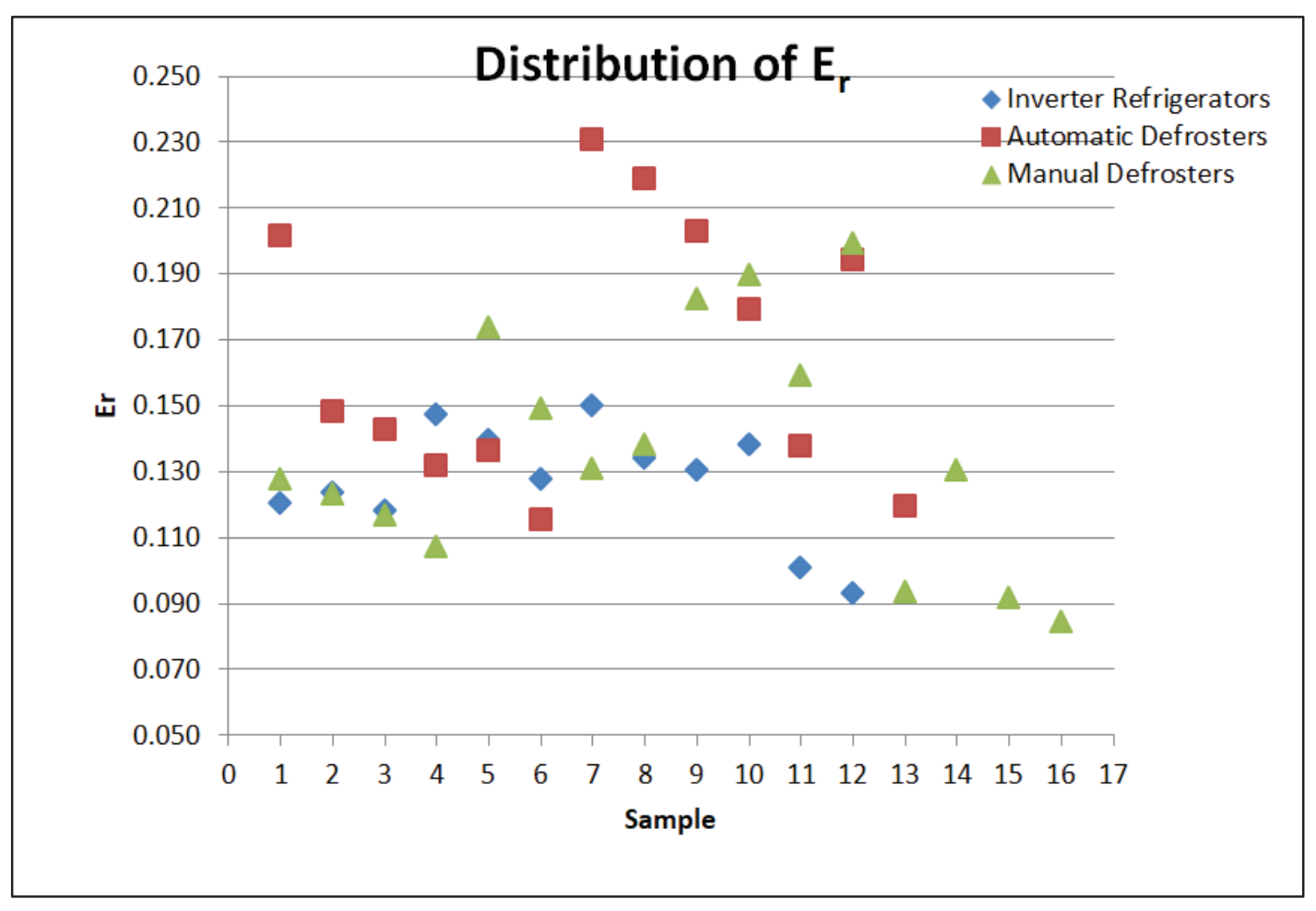

Figure 3 - Scatter Distribution of $E_{r}$ 


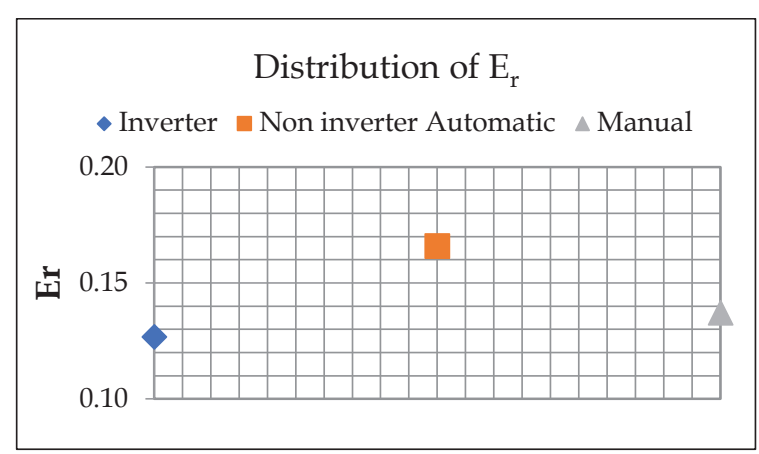

Figure 4 - Average Distribution of $\mathrm{E}_{\mathrm{r}}$

Energy consumption of inverter refrigerators was lower than non-inverter AD's, and further below of the manual defrosters. This was due to the adaptability of inverter refrigerator for the load requirement. Compartment temperature settings can be taken as one such situation. Though we need $-15^{\circ} \mathrm{C}$ at the freezer, the output average temperature at regulator settings is different for each refrigerator category. Figure 5 illustrates how the average temperature at freezer of each refrigerator category. The required average temperature was $-15^{\circ} \mathrm{C}$ for automatic defrosting refrigerators and $-9^{\circ} \mathrm{C}$ for manual defrosting refrigerators.

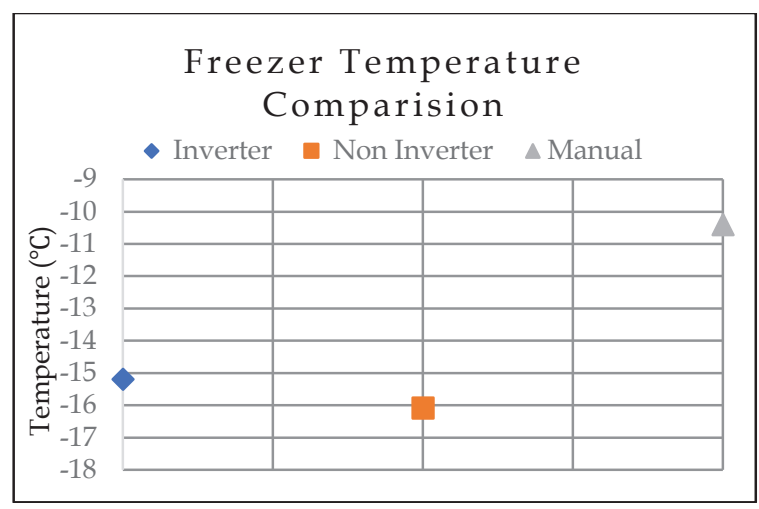

Figure 5 - Freezer Average Temperatures

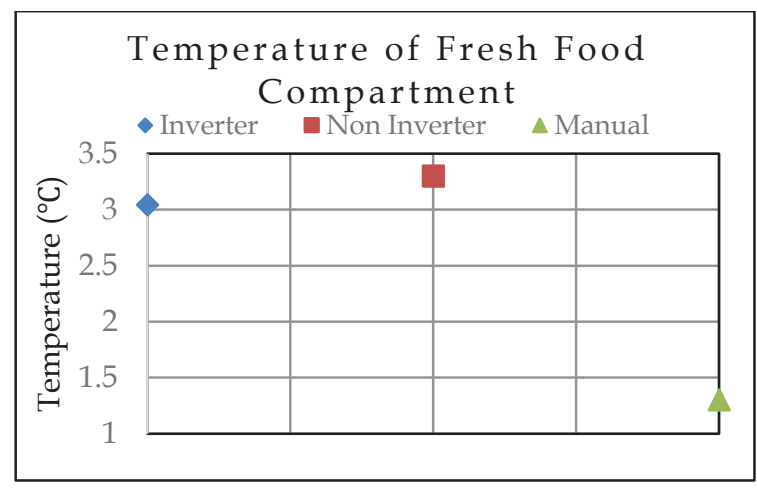

Figure 6 - Fresh Food Average Temperatures
Results show that fresh food compartment temperature of all the types of refrigerators to be lower than required, standard value being +5 (Figure 6). This has resulted in high energy consumption. Refrigerators should be technically improved to cater to this requirement.

\subsection{Potential Energy Saving at General Household}

\subsubsection{Analysis of manual and automatic defrosters}

During the test period, a graph for a manual defrosting refrigerator directly obtained from laboratory software is shown in Figure 7. Figure 8 shows that for a non-inverter based automatic defrosting refrigerator technology and Figure 9 shows a graph for inverter based automatic defrosting refrigerator. These graphical results inclusive of defrosting initiations for automatic defrosting refrigerators are as indicated in Figure 8 and 9.

Green color line is the power meter reading measurement. There are two sets of lines starting at room temperature; they are temperature sensors. Sensors at the refrigerator freezer, will drop to minus values and sensors at the fresh food compartment (FFC) drops to around $+5^{\circ} \mathrm{C}$. It is clear in the graph that manual defrosters have constant ON/OFF characteristics (green colour line) of the compressor.

Percentage increase in energy consumption for automatic defrosting refrigerators was calculated by considering difference in average energy efficiency rating as follows.

$$
\begin{aligned}
& =[(0.166-0.140) / 0.140] * 100 \\
& =18.5 \%
\end{aligned}
$$

Results indicate that automatic defrosting refrigerators consumes $18.5 \%$ more energy than manual defrosters. Manual defrosting operation is not considered here as the frequency of automatic defrosting operation is considerably higher than manual defrosting operation in even real situation in households. 


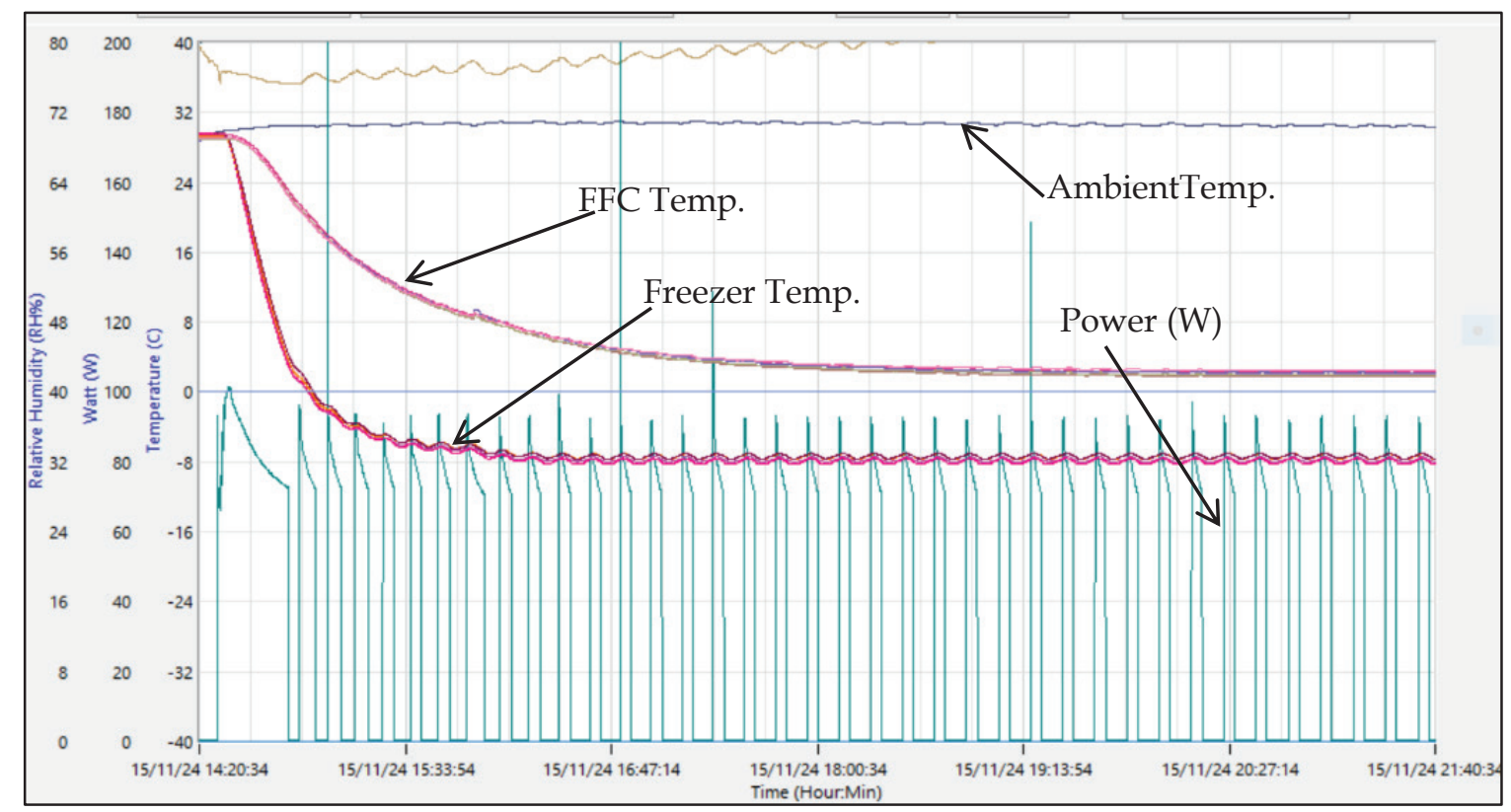

Figure 7 - Graph obtained for a Manual Defrost Refrigerator

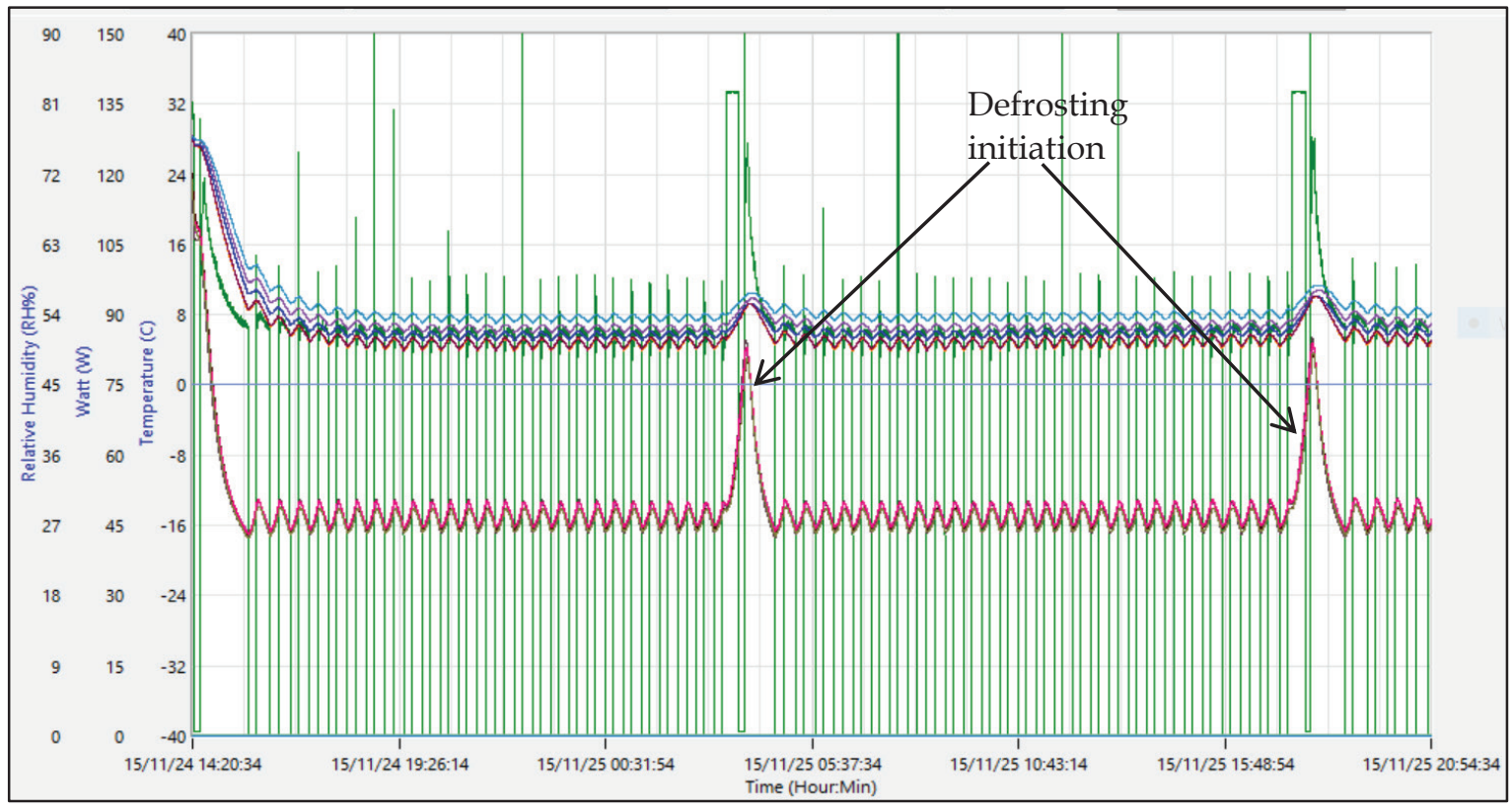

Figure 8 - Graph of an Automatic Defrost Refrigerator

\subsubsection{Comparison of inverter refrigerator} with non -Inverter automatic defrosting refrigerator

Test results of automatic defrosting refrigerators consist of defrosting cycles as shown in Figure 8. Increase in energy consumption after a specific time interval is due to the operation of defrosting heater which operates in a cyclic manner. At these points, temperature sensor readings have also instantaneously increased as shown in Figure 8. Inverter refrigerator has a variable speed compressor which shows a step fluctuation of power meter reading (green colour line) in Figure 9.

Energy Saving on inverter refrigerator against non -inverter $\mathrm{AD}=[(1.17-0.96) / 0.96]$ * 100

$$
=22 \%
$$

\subsubsection{Energy saving of inverter refrigerator} and manual defrosting refrigerator

Energy saving on inverter refrigerator against manual defrost refrigerator:

$$
\begin{aligned}
& =[(0.14-0.13) / 0.13] * 100 \\
& =10 \%
\end{aligned}
$$




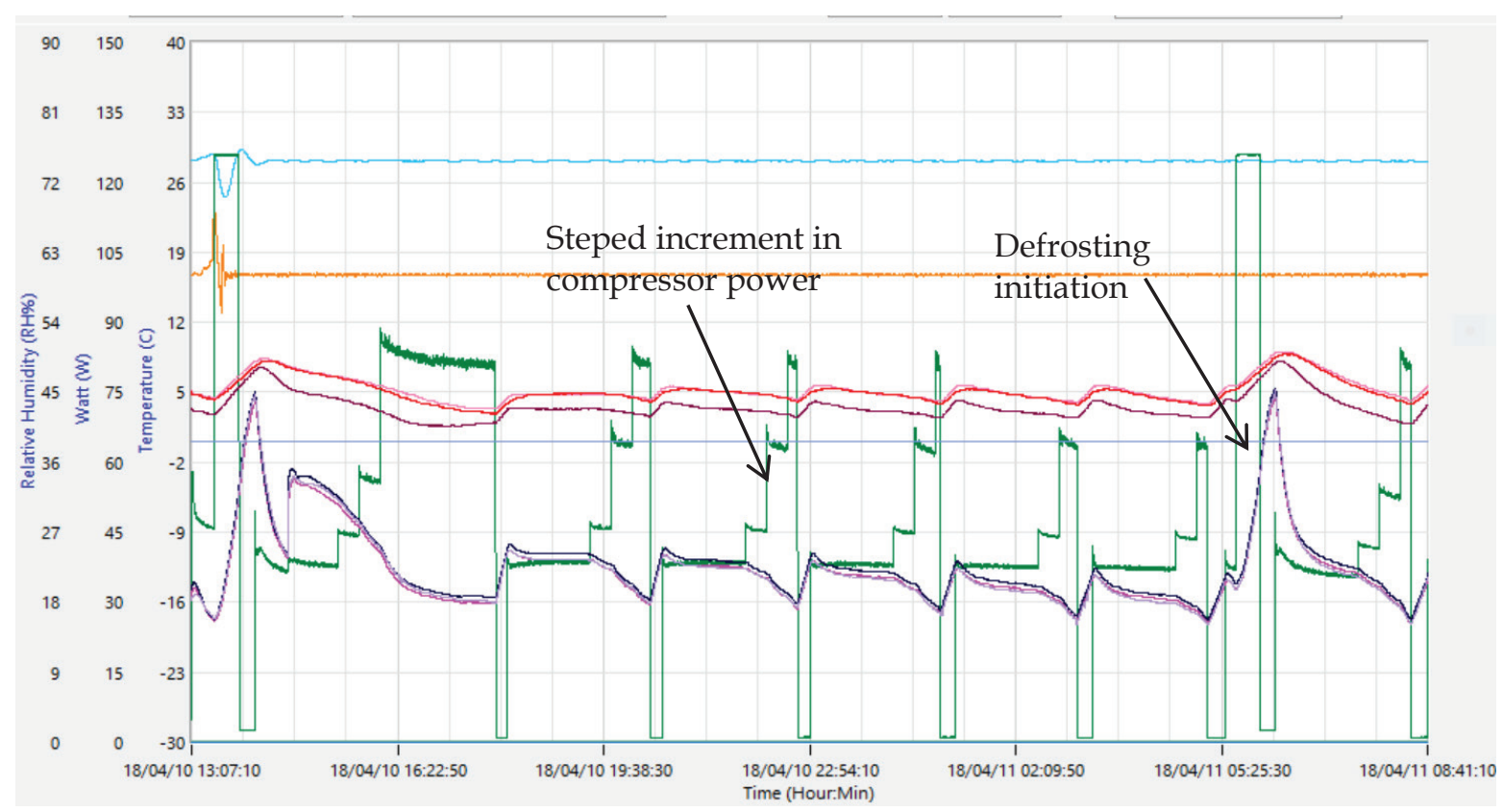

Figure 9 - Graph of an Inverter Refrigerator

\subsubsection{Energy saving of inverter refrigerator} based on model (Brand)

Calculated $E_{r}$ of inverter refrigerators were plotted model/brand wise (A, B, C and D) (Figure 10) and it was observed that there is no relationship for energy rating with refrigerator model or brand.

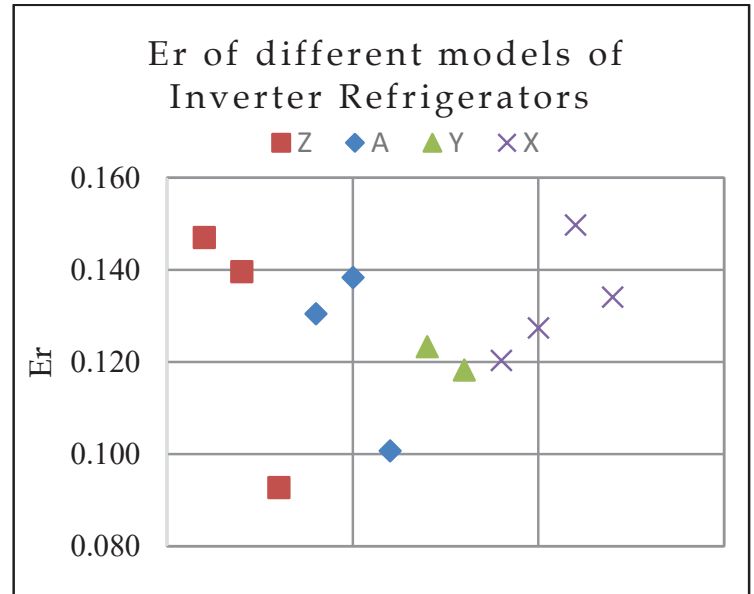

Figure 10 - Variation of Er with Inverter Refrigerator Models

\subsection{Potential Energy Saving}

If we consider the energy saving of the whole country, potential energy saving to reduce country power generation by considering 3.8milion households [3]:

Possible national saving:

$=3.8$ million* $(1.17-0.96) * 365$ units

$=291$ million units, can be saved annually.

\section{Conclusions}

This analysis was focused on identifying energy efficient refrigerators among key types of refrigerators available in the market. According to the analysis, refrigerators with inverter technology are $22 \%$ more energy efficient than normal automatic defrosting refrigerators and $10 \%$ more efficient than manual defrosting refrigerators. As inverter refrigerators are sensitive to the part loading situations, this analysis can be extended by including the loading pattern, door opening behavior and regulator positioning for future studies.

Further, as this analysis is based on experimental results, if we can do practical analysis by surveys then it will be helpful to obtain energy efficiency ratings more realistically. It will be further valuable if this analysis can extend to industrial and commercial type refrigerators other than domestic refrigerators.

\section{References}

1. Sri Lanka Standard Institution,Energy Efficiency Ratings of Household Refrigerator-Freezer and Freezer, SLS 1230:2003.

2. Barthel, C. and Thomas, C. (2012), Test Procedures, Measurements and Standards for Refrigerators and Freezers.

3. Housing and Sustainable Urban Development in Sri Lanka, Habitat III 2016 Sri Lanka National Report for Third United Nations - Conference -, Oct 2016, page 58 . 